\title{
The Status of Telomerase Enzyme Activity in Benign and Malignant Gynaecologic Pathologies
}

\author{
İlhami Gül', Özgür Dündar², Serkan Bodur³, Yusuf Tunca, Levent Tütüncü² \\ ${ }^{1}$ Department of Obstetrics and Gynaecology, Military Hospital, Erzincan, Turkey \\ ${ }^{2}$ Department of Obstetrics and Gynaecology, GATA Haydarpaşa Training Hospital, Istanbul, Turkey \\ ${ }^{3}$ Department of Obstetrics and Gynaecology, Mareşal Fevzi Çakmak Military Hospital, Erzurum, Turkey \\ ${ }^{4}$ Department of Medical Genetics, GATA Faculty of Medicine, Ankara, Turkey
}

\begin{abstract}
Background: Telomeres are essential for the function and stability of eukaryotic chromosomes. Telomerase consists of three subunits: human telomerase reverse transcriptase (hTERT), human telomerase RNA (hTR), and telomerase protein 1 (TP1). The hTERT subunit determines the activity of telomerase as an enzyme and is detected in most human tumors and regenerative cells. Telomerase activity is a useful cancer-cell detecting marker in some types of cancers.

Aims: The aim of this study was to assess of telomerase hTERT mRNA in gynaecological tumors for diagnosis of malignancy.

Study Design: Cross-sectional study.

Methods: A total of 55 gynaecologic tumor samples (35 ovarian, 13 endometrial, 6 cervical and 1 placental site trophoblastic tumor tissue) were obtained at the time of surgery. Quantification of hTERT mRNA was performed in a real-time reverse transcriptase polymerase chain reaction (RT-PCR) using the LightCycler TeloTAGGG hTERT Quantification Kit.

Results: It was histopathologically detected that 18 of the tissue samples were malignant and 37 of the samples were benign. 16 of the malignant tissue samples $(88.9 \%)$ and $3(8.1 \%)$ (endometrial tissue in proliferative phase, mucinous cyst adenoma and endometriosis) of the benign tissue samples were found to be hTERT positive. With the presence of these data, sensitivity and specificity of hTERT for the diagnosis of malignancy were calculated to be $88.9 \%$ and $91.9 \%$, respectively.
\end{abstract}

Conclusion: It was suggested that the measurement of telomerase activity in gynaecologic tumors, except for endometrial tissue in the reproductive phase, is a valuable method for pathological investigation.

Key Words: Telomerase, hTERT, gynecologic tumors, telomere, endometriosis

Received: 17.07.2012 Accepted: 10.05.2013

\section{Introduction}

The replication potential of the normal human cell line differs from the malignant cell line. There are two basic mechanisms that influence normal cell life span: the physiological conditions that interact with the cell and the genetically determined number of replications. The number of replications is associated with the length of the structures located at the ends of chromosomes, which are called telomeres. Telomeres are DNA protein complexes comprised of guanine-rich repetitive DNA sequences, located at the distal ends of the eukaryotic chromosomes (1).

Telomeres do not encode any proteins, but they do prevent cells from early aging by maintaining chromosome fractures and the end-to-end fusion of chromosomes (2). Every successful cell replication causes the loss of telomeres. A decrease in telomere length to a critical value initiates the aging process, resulting in programmed cell death (G0 phase) via the cessation of cell replication without disturbing normal metabolic activity (3).
The persistence of telomeres is attributable to the enzyme telomerase. The ribonucleoprotein (RNA) enzyme telomerase is composed of the following subunits: human telomerase reverse transcriptase (hTERT), human telomerase RNA (RNAhTR), and telomerase-associated protein 1 (TP1). The activity of the telomerase enzyme is in non-measurable levels in the majority of normal somatic cells (4), but activity reaches detectable levels in cells that have a high rate of replication, such as haematopoietic, cervical and endometrial cells (5).

The deterioration of the balance between telomeres and the telomerase enzyme, or activation of the telomerase enzyme, is a critical step in the development of cancer. Reported telomerase activities in many types of cancer, such as ovarian, bladder, lung, colorectal, gastric, hepatocellular, haematological, prostate, breast, cervical, endometrial and vaginal cancer, support the importance of this finding (5-9).

In this study, telomerase activity was measured in the tissue samples of patients who underwent surgery for any medical indication by the "Reverse Transcription Polymerase

This study was presented as a poster at the $62^{\text {nd }}$ Annual Meeting of Ametican Society for Reproductive Medicine, 21-25 October 2006, New Orleans, LA, USA.

Address for Correspondence: Dr. Özgür Dündar, Department of Obstetrics and Gynaecology, GATA Haydarpaşa Training Hospital, İstanbul, Turkey. Phone: +90 5324716483 e-mail: ozgurdundar72@yahoo.com 
Chain Reaction" (RT-PCR) method to determine the incidence of telomerase activity as a tumor marker.

\section{Material and Methods}

\section{Patient Group and Tissue Samples}

A total of 55 tissue samples gathered from 52 patients between the ages of 19-86 years, who underwent surgery for various reasons, were included in the study. The study was conducted in accordance with the principles of the Declaration of Helsinki and was carried out with the approval of the local Board of Ethics Committee. Each patient was included after confirmation of the "informed consent" certificate. Tissue samples taken during surgery were frozen in liquid nitrogen within three minutes. All samples were protected at $-80^{\circ} \mathrm{C}$ in order to be studied simultaneously. Patients who had received treatment which could potentially affect telomerase activity, such as chemotherapy, radiotherapy and hormone replacement therapy (HRT), and patients with concurrent malignancies were excluded from the study. All specimens were evaluated by a single pathologist, and all pathological diagnoses were confirmed by another pathologist at the conclusion of the study.

\section{Genetic Study}

The tissues were transported in $-78.5^{\circ} \mathrm{C}$ dry ice. Genetic analysis of samples was performed by a single genetic specialist at the Department of Medical Genetics, Molecular Genetics Laboratory. Genetic analysis was performed in two steps: isolation of total RNA and determination of messenger RNA (mRNA) expression level.

1.RNA isolation: RNA was isolated from tissues using the "High Pure RNA Tissue Kit" (Roche Diagnostics, Mannheim, Germany).

a.Preparation of samples: Ten $\mathrm{mg}$ of cross-sections was taken from the tissue samples, stored at $-80^{\circ} \mathrm{C}$, and pulverised with the aid of a mortar and liquid nitrogen. Four hundred $\mathrm{mL}$ of lysis/binding solution (4.5M guanidine- $\mathrm{HCl}, 100 \mathrm{mM} \mathrm{NaPO} 4, \mathrm{pH}$ 6.6) was added, and the pulverised tissue was homogenised with the aid of a micropipette.

The homogenate was transferred to $1.5 \mathrm{~mL} \mathrm{Ep}$ pendorf tubes and was centrifuged at $13000 \mathrm{rpm}$ for two minutes. The obtained supernatant was transferred to new $1.5 \mathrm{~mL}$ Eppendorf tubes and vortexed by adding $200 \mathrm{ml}$ of absolute ethanol. The obtained lysate was transferred to a filter spin-column and centrifuged at 13000 rpm for 30 seconds. In order to remove the DNA from the environment, $100 \mu \mathrm{L}$ of "DNase I" enzymes was added to the spin-column at room temperature $\left(25^{\circ} \mathrm{C}\right)$ and samples were incubated for 15 minutes. After incubation, $500 \mu \mathrm{L}$ of Washing Solution I $(5 \mathrm{M}$ guanidine- $\mathrm{HCl}, 20 \mathrm{mM}$ Tris- $\mathrm{HCl}, \mathrm{pH}$ 6.6) was added and centrifuged twice for 15 seconds each time at. The final washing was performed by adding $300 \mu \mathrm{L}$ of Washing Solution II $(20 \mathrm{mM} \mathrm{NaCl}$,
$2 \mathrm{mM}$ Tris- $\mathrm{HCl}, \mathrm{pH} 7.5)$ and by centrifugation at 13000 rpm for one minute. RNA was obtained by adding $100 \mu \mathrm{L}$ of eluting solution (nuclease-free bi-distilled water) to the spin-column and by centrifugation at 8000 rpm for one minute.

b.Quantitative determination of RNA: The obtained RNAs were diluted with bi-distilled water to maintain a 1/20 dilution ratio. The quantity and quality of RNA were determined by taking measurements with a spectrophotometer at 260 and $280 \mathrm{~nm}$ wavelengths.

2. Measurement of hTERT expression level: To evaluate the expression level of mRNAs encoding the hTERT, a real time PCR (RT-PCR) was performed using the "LightCyclerTeloTAGGGhTERT" quantification kit (Roche Diagnostics, Mannheim, Germany) and a "LightCycler" device.

RT-PCR of hTERT and porphobilinogendeaminase (PBGD) was performed using 300 ng RNA from each sample. The RT-PCR process was carried out by incubation of the "hTERT master mix" at $60^{\circ} \mathrm{C}$ for ten minutes. The full-length complementary DNA obtained was amplified for 50 cycles with fluorescent-labelled specific primers (amplification). Each cycle was composed of different periods: initiation $\left(95^{\circ} \mathrm{C}, 30\right.$ seconds), binding $\left(60^{\circ} \mathrm{C}\right.$, ten seconds), extension $\left(72^{\circ} \mathrm{C}\right)$, and termination $\left(40^{\circ} \mathrm{C}\right)$. The amplification level was determined by measuring the obtained fluorescence radiation with a device sensor. The level of hTERT mRNA expression was calculated using standard RNAs in the kit. In order to determine the true value of hTERT, the copy number of hTERT mRNA was indexed to the copy number of PBGD mRNA. Each reaction was verified using two positive RNA samples held in the original kit, and the possibility of contamination was ruled out using two negative samples (sterile distilled water) located in the kit. The results were expressed using software from the LightCycler instrument.

\section{Statistical Analysis}

SPSS v.12.0 (Chicago, IL, USA) was used for statistical analysis. The Mann-Whitney $U$ test was used for comparisons of hTERT values of benign and malignant neoplasms, and the Kruskal-Wallis test was used for comparisons of hTERT values of malignancies in different locations. In order to determine the diagnostic value of hTERT, a "receiver operating characteristics" (ROC) curve was drawn, and the area under the curve was calculated.

\section{Results}

The tissue samples of 115 patients who underwent surgery for various reasons were evaluated in this study. The samples of 16 patients could not be gathered due to improper conditions. Out of the remaining 99 patients, 22 were excluded from the study. Of those 22 patients, seven were excluded due to receiving radiotherapy and chemotherapy, four were 
Table 1. Demographic characteristics of the study population

\begin{tabular}{|lccc|}
\hline Feature & $\begin{array}{c}\text { Benign } \\
(\mathbf{n = 3 7 )}\end{array}$ & $\begin{array}{c}\text { Malign } \\
(\mathbf{n = 1 8 )}\end{array}$ & $\mathbf{p}$ \\
\hline Age (years, mean $\pm \mathrm{SD})$ & $47.5 \pm 10.8$ & $47.6 \pm 12.5$ & 0.634 \\
$\mathrm{BMI}\left(\mathrm{kg} / \mathrm{m}^{2}\right.$, mean $\left.\pm \mathrm{SD}\right)$ & $25.09 \pm 1.58$ & $25.77 \pm 2.01$ & 0.162 \\
Parity (mean $\pm \mathrm{SD})$ & $2.05 \pm 0.7$ & $2.02 \pm 1.4$ & 0.998 \\
Menopause rate $(\%)$ & 48.6 & 61.1 & 0.385 \\
The ratio of smoking (\%) & 48.6 & 61.1 & 0.385 \\
\hline
\end{tabular}

SD: Standard Deviation; BMI: Body Mass Index

Table 2. The diagnostic value of hTERT in differentiation of benign and malignant tissues

\begin{tabular}{|lccc|}
\hline hTERT & $\begin{array}{c}\text { Malign } \\
(\mathbf{n = 1 8})\end{array}$ & $\begin{array}{c}\text { Benign } \\
(\mathbf{n = 3 7 )}\end{array}$ & $\begin{array}{c}\text { Total } \\
(\mathbf{n = 5 5})\end{array}$ \\
\hline Positive & 16 & 3 & 19 \\
Negative & 2 & 34 & 36 \\
\hline
\end{tabular}

excluded due to the presence of an extra-genital malignancy, and 11 were excluded due to having undergone hormone replacement therapy (HRT).

The 77 patients who were eligible for inclusion in the study in accordance with inclusion criteria were divided into two groups: benign and malignant. RNA could not be isolated in five malignant and 17 benign tissue samples, which meant that the study was completed with 55 tissue samples from 52 patients (Figure 1).

Nineteen of the 55 tissue samples (34.5\%) were malignant, and 36 (65.5\%) were benign pathologies. The anatomic distribution of tissue samples was as follows: placenta $(1 / 55,1.8 \%)$, cervix $(6 / 55,10.9 \%)$, endometrium $(13 / 55,23.7 \%)$ and ovary $(35 / 55,63.6 \%)$. There was no statistically significant difference in the demographic characteristics (age, smoking rate, parity, abortion, menopausal status, and body mass index (BMI)) of the two groups (Table 1).

hTERT was found positive in a total of 18 tissue samples (34.5\%) and negative in a total of 37 tissue samples (65.5\%) when values greater than zero were accepted as positive. Of the 18 hTERT positive tissue samples, 16 (88.9\%) were malignant and two (8.1\%) were benign. hTERT was considered negative in three of the malignant and 34 of the benign tissue samples. When hTERT positivity was used as a criterion of malignancy, sensitivity, specificity, positive predictive value, and negative predictive values were calculated to be $88.9 \%$, $91.9 \%, 84.2 \%$, and $94.4 \%$, respectively (Table 2 ).

Six of the 55 tissue samples were derived from the cervix. While five of these cervical samples were reported malignant, one was reported benign. Histopathologically, four of the five malignant cervical pathologies were reported as cervical squamous cell carcinoma, and one malignant cervical tissue was evaluated as endocervical adenocarcinoma. All malignant cervical pathologies were hTERT positive, except one cervical squamous cell carcinoma (80\%). The benign cervical tissue

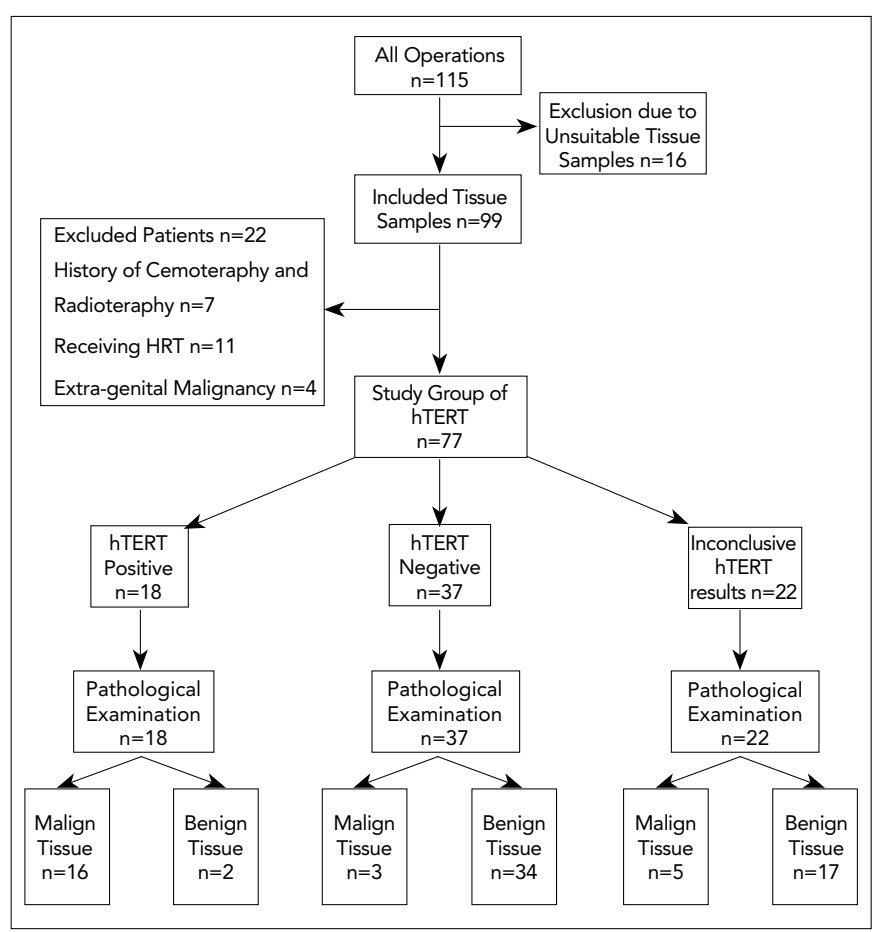

Figure 1. Study Flow Chart

sample, diagnosed as microglanduler endocervical hyperplasia, was found to be hTERT negative.

Thirteen of the 55 tissue samples originated from the endometrium. Of those tissue samples, six were malignant and seven were benign. Histopathological examination of malignant tissue samples showed five endometrioid endometrial adenocarcinoma and one signet ring cell carcinoma. All malignant endometrial pathologies were found to be hTERT positive (100\%). Histopathological evaluation of benign endometrial tissue samples showed six endometrial polyps and one irregular proliferative-phase endometrium; hTERT positivity was found only in the irregular proliferative phase endometrium (14.2\%).

Thirty five of the 55 tissue samples were taken from the ovaries. Among these 35 ovarian tissue samples, six were malignant and 29 were benign pathologies. Histopathologically, of the six malignant tissue samples, four were serous papillary adenocarcinomas, one was a mucinous adenocarcinoma, and one was a borderline mucinous cystadenoma. hTERT positivity was determined in all of the malignant ovarian tissue samples (100\%). There were four ovarian serous simple cysts, five serous cystadenomas, three mature cystic teratomas, two corpus haemorrhagic cysts, one tekoma, one mucinous cyst adenoma, and 13 endometrioses among the benign pathologies. hTERT was considered positive in one endometriosis and one mucinous cystadenoma tissue sample (6.9\%).

When endometriosis was considered a separate subgroup, hTERT positivity was found in one of the 13 endometriosis tissue samples (7.7\%).

hTERT positivity could not be detected in any placental site trophoblastic tumor tissue sample.

hTERT positivity was determined in four of the five malignant cervical tissue samples (80\%), in all six malignant ovarian tissue samples (100\%), in all six malignant endometrial tissue 


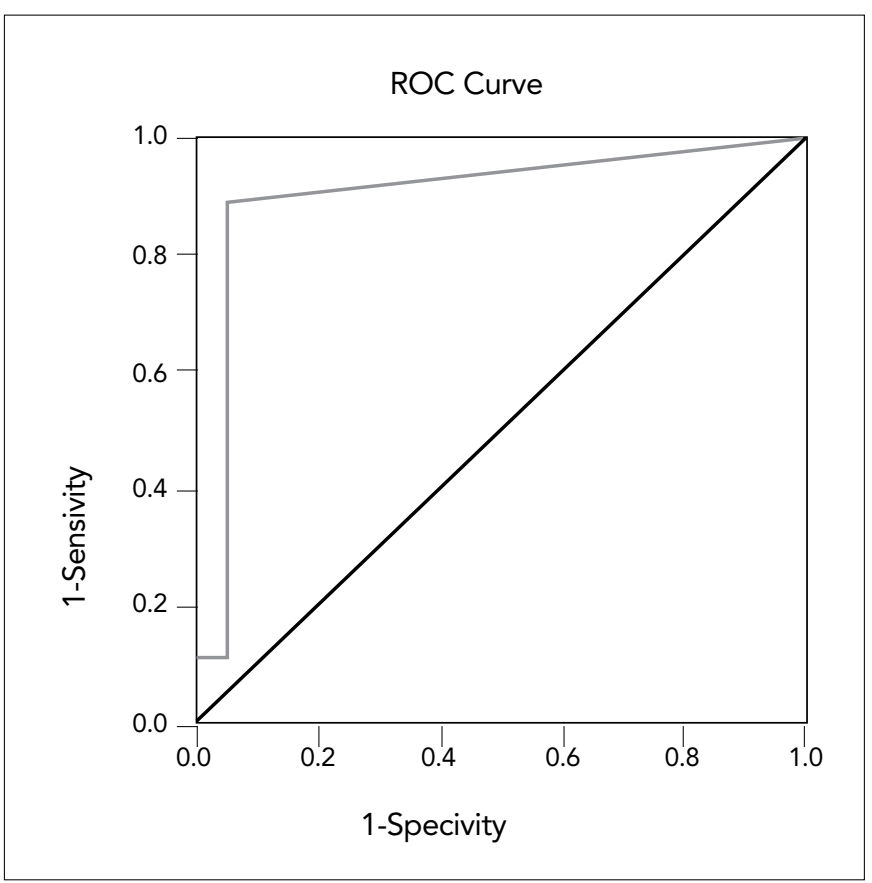

Figure 2. ROC curve of hTERT

samples (100\%), in one of the seven benign endometrial tissue samples (14.2\%), and in two of the 29 benign ovarian tissue samples (6.9\%). A total of 19 of the 55 tissue samples were found to be hTERT positive (34.5\%).

The area under the ROC curve was calculated to be 0.897 if the diagnosis of malignancy was obtained by hTERT levels (Figure 2).

\section{Discussion}

Studies conducted on normal cervical tissue samples, as well as samples of cervical inflammation (cervicitis), premalignant lesions and cervical malignancies, determined telomerase activity to be between $0-96.4 \%$ and $61.9-100 \%(6,10-13)$. Cervico-vaginal smear screening is a routinely used technique for cervical malignancy screening with high false negative rates due to the negative effects of inflammation, bleeding and tissue residues. The measurement of telomerase activity has been suggested to be useful in the diagnosis of early stage cervical premalignant lesions (6).

Microglandular endocervical hyperplasia was the sole benign cervical lesion included in this study, and hTERT activity was found to be negative in this benign cervical tissue sample. Therefore, hTERT activity can be used to confirm or support the identification of endocervical hyperplasia.

In this study, four of five malignant cervical tissue samples were considered hTERT positive (80\%), and this finding was in correlation with the relevant literature. hTERT positivity was found in one endocervical adenocarcinoma sample and in three cervical squamous cell carcinoma samples. hTERT was found to be negative in the case of early stage cervical squamous cell cancer. This result can be explained by the ALT mechanism. In order to verify this finding, telomere length measurement studies need to be performed in conjunction with telomerase activity.
Although normal endometrial tissue has a somatic origin, it displays variable telomerase activity depending on the period of the menstrual cycle $(6,14)$. While the highest level of telomerase activity was noticed in the proliferative phase of the normal cyclic endometrial tissue, the lowest level of telomerase activity was found during menstruation. Potent telomerase activity was detected in patients with endometrial cancer (14). The positivity rate of telomerase activity was reported in various studies to be between $0-9 \%, 25 \%, 10-58 \%, 67-92 \%$, and $83-100 \%$ during menopause, menstruation, secretory phase, proliferative phase, and endometrial malignancies, respectively $(6,15,16)$. The measurement of telomerase activity was found to be primarily impractical during the proliferative phase of the endometrium.

There were seven benign endometrial lesions in this study, and hTERT positivity was detected in only one benign endometrial tissue (14.2\%), which was histologically reported as an irregular proliferative endometrium. Due to the high level of hTERT positivity, the tissue sample was re-evaluated against the possibility of malignancy. There was no evidence of malignancy noted. This finding was consistent with the existing literature, which has documented high telomerase activity rates in late proliferative phase endometrial tissues. The remaining benign tissue samples were reported to be endometrial polyps, and none were found to be hTERT positive.

Telomerase activity was determined to be between $14.2 \%$ and $80 \%$ in premalignant endometrial tissue samples, and the positivity rate was generally higher in lesions with cellular atypia $(15,17)$. There was no premalignant endometrial sample in this study, but the results of a study conducted among the Turkish population were parallel with current literature published in the English language (18). In this study, all six malignant endometrial tissue samples (100\%) were found to be positive for hTERT. The positivity rate of telomerase activity in endometrioid adenocarcinoma was reported to be between $70 \%$ and $100 \%$ in previous studies $(15,17,18)$.

Ovarian tumors are classified as benign, borderline and malignant (19). Usually, there is no detectable telomerase activity in normal ovarian tissue. In benign ovarian pathologies such as mucinous cyst adenoma, the positivity of telomerase activity was found to be between $0 \%$ and $36.3 \%$ in association with proliferation (19-22). In the same trials, $67 \%$ to $100 \%$ telomerase activity was detected in borderline tumors. These results were considered evidence of a malignant process in borderline tumors at the molecular level. Telomerase activity was determined in $71.4 \%$ to $100 \%$ of malignant ovarian tumors. It was thought that measurement of telomerase activity could provide benefits in early diagnosis, in monitoring the response to treatments, in confirming the pathological diagnosis, and also in the follow-up treatment of relapses (19-21).

In this study, high levels of telomerase enzyme activity were determined in one mucinous cystadenoma (6.25\%), but there was no enzyme activity noticed in five of the serous cystadenoma samples among 16 benign ovarian malignancies. There were no borderline tissue samples diagnosed in this study. There was a total of five malignant tissue samples in this study; histopathologically, four were ovarian serous papillary 
adenocarcinomas, and one was a mucinous adenocarcinoma. All histopathological subtypes were positive for telomerase activity (100\%).

While malignant ovarian cells could be detected in 26 out of $47(55.3 \%)$ of the abdominal washing fluid specimens, telomerase activity was positive in 29 of the same specimens $(61.7 \%)$ in a study designed to reveal the value of telomerase activity in cytological investigation (23). Re-evaluation of the specimens by histopathological examination revealed the presence of ovarian malignancy in those additional three telomerase activity-positive washing fluid specimens. Furthermore, telomerase activity was positive in all of the pathological malignant specimens. In another study, telomerase activity was found to be positive in $88 \%$ of the abdominal washing fluids of surgical ovarian malignancy patients (24). This finding showed the sensitivity and diagnostic value of telomerase activity in minimal residual disease. This study was done with solid tissues because telomerase activity in cytology specimens is beyond the spectrum of this study.

In this study, the comparison of telomerase activity according to anatomical location or site revealed that the highest concentrations of telomerase activity were found in endometrial malignancies. Endometrial malignancies were followed by cervical and ovarian malignancies in terms of telomerase activity level, respectively. The comparison of these three anatomic locations revealed a statistically significant difference between endometrial malignancies and ovarian malignancies $(p=0.018)$. All specimens of endometrial malignancies that were found to be positive for hTERT activity were from menopausal women who did not take HRT. The presence of enzyme activity in the absence of hormonal influence revealed the diagnostic value of assessing telomerase enzymes in endometrial malignancies.

Malignancies and endometrioses are separate entities with different clinical behaviours, but endometriosis and malignancies share many common features, such as the presence of cellular atypia, adhesion, invasion and metastasis. Additionally, existing studies have documented instances of malignant transformation in endometriosis and malignancies arising from endometriosis, particularly ovarian cancers (25, 26). Some studies have suggested that endometriotic lesions show resistance to apoptotic signals together with a capacity for unlimited replication, much like malignant tissues (26-28). Because of these findings, endometriosis was proposed to be a premalignant disease with the likelihood of progression to malignancy. In normal somatic cell lines, the gradual shortening of telomeres due to multiple cell replications results in cell aging and death. Telomerase enzyme activity can prevent telomeres from shortening in endometriotic lesions and lead them to achieve unlimited replication rates, much like many types of malignancies. Oestrogen and progesterone have been reported to increase levels of the telomerase enzyme in breast and endometrial cancer in a state of p53 inhibition in accompaniment with the use of tamoxifen (29).

In this study, hTERT positivity was determined in only one of 13 endometriosis specimens (7.7\%). Endometriotic tissue with low hTERT activity was reassessed histopathologically against the $0.7 \%$ probability of malignancy and the presence of atypical cells as reported in the literature (26). However, no atypical cells could be observed histopathologically, and low hTERT positivity was thought to be an early molecular switch in the malignant process.

In this study, when hTERT positivity was used as a criterion for malignancy, sensitivity, specificity, positive predictive value, and negative predictive value were calculated as $88.9 \%, 91.7 \%$, $84.2 \%$ and $94.3 \%$, respectively. In another study conducted on the efficacy of telomerase activity in diagnosing malignancy, the sensitivity and specificity of positive telomerase enzyme activity was determined to be $87 \%$ and $95 \%$, respectively (30). The sensitivity and specificity rates of both studies are nearly parallel to one another. It is our belief, therefore, that this test has been shown to be successful in predicting malignancy and also holds promise in terms of future clinical use.

Telomerase activity was reported to be between $12.5 \%$ and $86.7 \%$ in complete moles and $100 \%$ in choriocarcinomas (30-32). In this study, hTERT activity was found to be negative in the single gestational trophoblastic tissue sample; we believe that this was related to the low proliferation rate of gestational trophoblastic diseases and may also indicate a favourable prognosis for the disease.

In conclusion, and in light of our findings, hTERT measurement was determined to be beneficial for the evaluation of gynaecological malignancies. Accordingly, the use of hTERT measurements has been proven to be more appropriate when limited to postmenopausal endometrial malignancies.

Ethics Committee Approval: Ethics committee approval was received for this study from the ethics committee of Gülhane Military Medical Academy.

Informed Consent: Written informed consent was obtained from patients who participated in this study.

Peer-review: Externally peer-reviewed.

Author contributions: Concept - I.G., L.T.; Design - i.G., L.T., Y.T.; Supervision - I.G., L.T., Y.T.; Resource - I.G.,L.T.; Materials - I.G., L.T., Y.T.; Data collection\&/or Processing - I.G., L.T., Y.T.; Analysis\&/or Interpretation - I.G., L.T., Y.T., Ö.D.; Literature Search - I.G., S.B., Ö.D.; Writing - I.G., L.T., S.B., Ö.D.; Critical Reviews - I.G., L.T., Ö.D., S.B., Y.T.

Conflict of Interest: No conflict of interest was declared by the authors.

Financial Disclosure: This study was supported by Gülhane Military Medical Academy Haydarpaşa Training Hospital.

\section{References}

1. Greider CW, Blackburn EH. Telomeres, telomerase and cancer. Sci Am 1996;274:92-7. [CrossRef]

2. Blackburn EH. Switching and signaling at the telomere. Cell 2001;106:661-73. [CrossRef]

3. Goldstein S. Replicative Senescence: The Human Fibroblast Comes of Age. Science 1990;249:1129-33. [CrossRef]

4. Shay JW, Zou Y, Hiyama E, Wrigw E. Telomerase and Cancer. Hum Mol Genet 2001;10:677-85. [CrossRef]

5. Shay JW, Bacchetti S. A survey of Telomerase Activity in Human Cancer. Eur J Cancer 1997;33:787-91. [CrossRef]

6. Miura N, Kanamori Y, Takahashi M, Sato R, Tsukamoto T, Takahashi $\mathrm{S}$, et al. A diagnostic evaluation of serum human telomerase reverse transcriptase mRNA as a novel tumor marker for gynecologic malignancies. 2007;17:541-8.

7. Carroll KA, Ly H. Functional characterization of mutations in the promoter proximal region of the telomerase hTERC gene identi- 
fied in patients with hematological disorders. Int J Clin Exp Med 2011;4:187-92.

8. Adler S, Rashid G, Klein A. Indole-3-carbinol inhibits telomerase activity and gene expression in prostate cancer cell lines. Anticancer Res 2011;31:3733-7.

9. Elenbaas B, Spirio L, Koerner F, Fleming MD, Zimonjic DB, Donaher JL, et al. Human breast cancer cells generated by oncogenic transformation of primary mammary epithelial cells. Genes Dev 2001;15:50-65. [CrossRef]

10. Jarboe EA, Liaw KL, Thompson LC, Heinz DE, Baker PL, McGregor JA, et al. Analysis of telomerase as a diagnostic biomarker of cervical dysplasia and carcinoma. Oncogene 2002;21:66473. [CrossRef]

11. Mutirangura $A$, Sriuranpong $V$, Termrunggraunglert $W$, Tresukosol D, Lertsaguansinchai P, Voravud N, et al. Telomerase activity and human papillomavirus in malignant, premalignant and benign cervical lesions. Br J Cancer 1998;78:933-9. [CrossRef]

12. Nagai N, Oshita T, Murakami J, Ohama K. Semiquantitative analysis of telomerase activity in cervical cancer and precancerous lesions. Oncol Rep 1999;6:325-8.

13. Wisman GBA, Hollema $H$, de Jong $S$, ter Schegget J, Tjong-AHung SP, Ruiters $\mathrm{MHJ}$, et al. Telomerase activity as biomarker for (pre)-neoplastic cervical disease in scrapings and frozen sections from patients with abnormal cervical smears. J Clin Oncol 1998; 16:2238-45.

14. Lehner R, Enomoto T, McGregor JA, Shroyer AL, Haugen BR, Pugazhenthi U, et al. Quantitative Analysis of Telomerase hTERT mRNA and TelomeraseActivity in Endometrioid Adenocarcinoma and in Normal Endometrium. Gynecologic Oncology 2002;84:120-5. [CrossRef]

15. Shroyer KR, Stephens JK, Silverberg SG, Markham N, Shroyer AL, Wilson ML, Enomoto T. Telomerase expression in normal endometrium, endometrial hyperplasia, and endometrial adenocarcinoma. Int J Gynecol Pathol 1997;16:225-32. [CrossRef]

16. Williams CD, Boggess JF, Lamarque LR, Meyer WR, Murray MJ, Fritz MA, Lessey BA. A Prospective, Randomized Study of Endometrial Telomerase During the Menstrual Cycle. The J Clin Endocrinol Metab 2001;86:3912-7. [CrossRef]

17. Brustmann H. Immunohistochemical Detection of Human Telomerase Reverse Transcriptase (hTERT), Topoisomerase II $\alpha$ Expression, and Apoptosis in Endometrial Adenocarcinoma and Atypical Hyperplasia. Int J Gynecol Pathol. 2005;24:184-92. [CrossRef]

18. Saygan-Karamursel B, Dikmen G, Dogan P, Aksu T, Guven S, Ayhan A. Quantitative telomerase activity in malignant, benign and normal gynecological tissues. Eur J Gynaecol Oncol 2005;26:83-6.

19. Datar RH, Naritoku WY, Li P, Tsao-Wei D, Groshen S, Taylor CR, et al. Analysis of telomerase activity in ovarian cystadenomas, lowmalignant-potential tumors, and invasive carcinomas. Gynecol Oncol 1999;74:338-45. [CrossRef]
20. Baykal A, Thompson JA, Xu XC, Hahn WC, Deavers MT, Malpica $A$, et al. In situ human telomerase reverse transcriptase expression pattern in normal and neoplastic ovarian tissues. Oncol Rep 2004;11:297-302.

21. Oishi T, Kigawa J, Minagava Y, Shimada M, Takahashi M, Terakawa N. Alteration of Telomerase Activity associated with development and extention of epitelyal ovaryan cancer. Obstet Gynecol, 91(4): 568-71, 1998. http://dx.doi.org/10.1016/S00297844(98)00044-1. [CrossRef]

22. Wan M, Li W, Duggan B, Felix JC, Zhao Y, Dubeau L. Telomerase Activity in Benign and Malignant Epithelial Ovarian Tumors. J Natl Cancer Inst, 89: 437-41, 1997. http://dx.doi.org/10.1093/ jnci/89.6.437 PMid:9091645. [CrossRef]

23. Tseng CJ, Jain S, Hou H, Liu W, Pao C, Lin C, et al. Applications of the Telomerase Assay in Peritoneal Washing Fluids. Gynecol Oncol 2001;81:420-3. [CrossRef]

24. Duggan B, Wan M, Martin SE, Yu M, Kanel G, Muderspach LI. Sensitive detection of ovarian carcinoma cells by measurement of telomerase activity in ascites or pelvic-peritoneal washings. Proc Am Assoc Cancer Res 1997;38:106.

25. Gazvani R, Templeton A. Peritoneal environment, cytokines and angiogenesis in the pathophysiology of endometriosis. Reproduction 2002;123:217-26. [CrossRef]

26. Zafrakas M, Tarlatzis BC, Streichert T, Pournaropoulos F, Wölfle $U$, Smeets SJ, et al. Genome-wide microarray gene expression, array-CGH analysis, and telomerase activity in advanced ovarian endometriosis: a high degree of differentiation rather than malignant potential. Int J Mol Med 2008;21:335-44.

27. Hapangama DK, Turner MA, Drury JA, Quenby S, Saretzki G, Martin-Ruiz $C$, et al. Endometriosis is associated with aberrant endometrial expression of telomerase and increased telomere length. Hum Reprod 2008;23:1511-9. [CrossRef]

28. Mormile R, Vittori G. Endometriosis: a crosstalk between epidermal growth factor (EGF) gene polymorphism and telomerase activity? Eur J Obstet Gynecol Reprod Biol 2011;159:482-3. [CrossRef]

29. Vercellini P, Parazzini F, Bolis G, Carinelli S, Dindelli M, Vendola $\mathrm{N}$, et al. Endometriosis and ovarian cancer. Am J Obstet Gynecol 1993;169:181-2. [CrossRef]

30. Counter CM, Meyerson M, Eaton E, Ellisen L, Caddle S, Haber $D$, et al. Telomerase activity is restored in human cells by ectopic expression of hTERT (hEST2), the catalytic subunit of telomerase. Oncogene 1998;16:1217-22. [CrossRef]

31. Cheung AN, Zhang DK, Liu Y, Ngan HY, Shen DH, Tsao SW. Telomerase activity in gestational trophoblastic disease. J Clin Pathol 1999;52:588-92. [CrossRef]

32. Nishi H, Yahata N, Ohyashiki K, Isaka K, Shiraishi K, Ohyashiki JH, et al. Comparison of telomerase activity in normal chorionic villi to trophoblastic diseases. Int J Oncol 1998;12:81-5. 